Bài báo khoa hoc

\title{
Nghiên cứu ảnh hưởng của các yếu tố địa chất, thủy văn đến ổn định bờ sông Cái Vừng, huyện Hồng Ngụ̣, tỉnh Đồng Tháp
}

\author{
Lê Hải Bằng ${ }^{1}$, Lâm Văn Thịnh², Lê Hải Trín ${ }^{3}$, Đinh Văn Duy ${ }^{3}$, Trần Văn Tỳ ${ }^{3 *}$, Huỳnh \\ Vương Thu Minh ${ }^{2}$
}

${ }^{1}$ Sở Nông nghiệp \& Phát triển Nông thôn tỉnh Đồng Tháp; lehaibangcctl@gmail.com.

${ }^{2}$ Khoa Môi trường \& Tài nguyên Thiên nhiên, Trường Đại học Cần Thơ; lvthinh@ctu.edu.vn; hvtminh@ctu.edu.vn.

3 Khoa Công nghệ, Trường Đại học Cần Tho; tvty@ctu.edu.vn; dvduy@ctu.edu.vn; lehaitri@gmail.com.

*Tác giả liên hệ: tvty@ctu.edu.vn; Tel.: +84-939501909.

Ban Biên tập nhận bài: 8/7/2021; Ngày phản biện xong: 19/8/2021; Ngày đăng bài: $25 / 11 / 2021$

Tóm tắt: Mục tiêu của nghiên cứu này là đánh giá hiện trạng sạt lở và ảnh hưởng của dao động cao độ nước dưới đất đến ổn định bờ sông Cái Vừng, huyện Hồng Ngự, tỉnh Đồng Tháp. Các số liệu về địa hình, địa chất, thủy văn được thu thập, đo đạc để phân tích, thiết lập tương quan giữa cao độ nước dưới đất và mực nước sông; từ đó phân tích nguyên nhân sạt lở thông qua hệ số ổn định. Kết quả cho thấy nguyên nhân chính là do dòng chảy, địa chất yếu cùng với sự dao động cao độ nước dưới đất. Vận tốc dòng chảy có biểu đồ phân bố lệch tâm, tạo ra dòng chảy xiên với lưu tốc lớn nhất gần bờ lớn hơn vận tốc không xói cho phép tương ứng với cỡ hạt theo TCVN 4118-2012. Lớp đất yếu nằm trong giới hạn dao động mực nước triều cùng với dòng chảy lệch tâm tạo ra các lỗ rỗng và ngày càng bị khoét sâu gây mất ổn định bờ sông. Hệ số ổn định trong các trường hợp đều nhỏ hơn giá trị cho phép. Kết quả nghiên cứu dựa trên số liệu đo đạc trong thời gian ngắn nên chưa thể đánh giá đầy đủ các nguyên nhân có thể ảnh hưởng đến sạt lở bờ sông. Vì vậy, cần quan trắc liên tục hoặc theo các mùa để có đánh giá chính xác hơn nguyên nhân sạt lở.

Từ khóa: Đất yếu; Hệ số ổn định; Dao động cao độ nước dưới đất; Sông Cái Vừng; Vận tốc dòng chảy.

\section{Mở đầu}

Đồng bằng sông Cửu Long (ĐBSCL) là một trong ba đồng bằng lớn nhất thế giới với diện tích lên đển $60.000 \mathrm{~km}^{2}$ và có một mạng lưới sông ngòi dày đặc [1]. Trong những năm gần đây, tình trạng xâm nhập mặn và thay đổi chế độ dòng chảy do biến đổi khí hậu (BĐKH) là một trong những thách thức cho vùng ĐBSCL. Hệ thống đê bao và hạ tầng công trình thủy lợi đã được xây dựng ở ĐBSCL từ những năm 1990 nhằm giúp tăng mùa vụ và giảm thiểu tác động của lũ hàng năm ở các vùng thượng nguồn. Cùng với sự phát triển kinh tế, các khu dân cư, đường giao thông, các thành phố cùng với các dịch vụ giải trí được xây mới và mở rộng đã dần dần thu hẹp diện tích rừng, mặt đệm và mặt nước. Bên cạnh đó, việc mở rộng diện tích canh tác, khu công nghiệp và xây các đập thủy điện ở các quốc gia thượng nguồn đã làm giảm nguồn nước và phù sa và đồng thời làm gia tăng thêm nguồn ô nhiễm nước mặt đến ĐBSCL [2]. Việc giảm hàm lượng phù sa trên sông không chỉ ảnh hưởng đến năng suất cây trồng mà còn ảnh hưởng đến sụt lún và sạt lở các sông/kênh rạch ở ĐBSCL. 
Một số nghiên cứu gần đây như nghiên cứu sử dụng công thức kinh nghiệm để tính toán thử nghiệm mức độ sạt lở cho đoạn sông Hậu ở thành phố Long Xuyên, tỉnh An Giang [3]; nghiên cứu dự báo xói lở, bồi lắng lòng dẫn và đề xuất các biện pháp phòng chống cho hệ thống sông ĐBSCL [4]; nghiên cứu ứng dụng mô hình toán và công thức kinh nghiệm đánh giá sự phát triển của hố xói sâu hạ lưu sông Hậu và sông Vàm Nao [5]; nghiên cứu ứng dụng mô hình SWAT trong tính toán xói lở bề mặt lưu vực hạ lưu sông Mekong [6]; nghiên cứu công thức kinh nghiệm tính tốc độ xói lở bờ đoạn sông Tiền khu vực Thường Phước, tỉnh Đồng Tháp [7]; nghiên cứu tương quan xói lở-bồi tụ một số khu vực lòng sông Tiền, sông Hậu [8]; và nghiên cứu mối quan hệ giữa khai thác cát với biến động bờ sông Tiền tại tỉnh Đồng Tháp [9].

Nguyên nhân chủ yếu gây sạt lở và xói mòn bờ sông ở ĐBSCL rất đa dạng như do dòng chảy, mưa, cấu tạo địa chất bờ sông, hình thái lòng dẫn, tải trọng tác dụng lên bờ sông, ... Thực tế cho thấy, có những khu vực sạt lở gây ra do dòng chảy ép sát bờ được tìm thấy ở Tân Châu, Mỹ Thuận, Sa Đéc, Mỹ Khánh; nhiều khu vực khác lại do sóng tàu đi lại gây nên được tìm thấy ở sông Chợ Gạo ở Tiền Giang, kênh KH6, rạch Cái Sơn ở Cần Thơ; hay do kết cấu đất bờ yếu, hoặc do các tổ hợp bất lợi từ nhiều yếu tố được tìm thấy ở Vàm Nao, Long Xuyên; và do nhà lấn chiếm lòng dần ở Trà Nóc, Trà An [10]. Sạt lở bờ sông Tiền đoạn chảy qua địa bàn tỉnh Đồng Tháp đang xảy ra ngày càng trầm trọng dưới tác động của các yếu tố tự nhiên và con người [11]. Một số nghiên cứu cho thấy sạt lở bờ sông cần được đánh giá dựa trên sự cân bằng bùn cát trong sông và tác động tổ hợp của các yếu tố gây sạt lở bờ sông lên từng vị trí cụ thể là không giống nhau. Vì vậy, cần xác định được thời điểm, tần suất và cường độ tác động của từng nguyên nhân lên sạt lở bờ sông tại một vị trí nhất định [12].

Nhìn chung, các nghiên cứu trước đây tập trung chủ yếu vào nguyên nhân sạt lở trên hai dòng sông chính của ĐBSCL là sông Tiền và sông Hậu. Một vài nghiên cứu nguyên nhân sạt lở các chi lưu của sông Mekong. Sông Cái Vừng (ranh giới tỉnh An Giang và Đồng Tháp) là nguồn cung cấp nước sinh hoạt, sản xuất và là tuyến giao thông quan trọng để vận chuyển hàng hóa từ các xã ven sông ra bên ngoài bằng đường thủy. Sông có đặc điểm là quanh co gấp khúc, địa hình đáy sông trong các năm qua đã có sự biến động lớn [13]. Sự bồi tích phù sa mạnh mẽ bên bờ thuộc tỉnh An Giang, ở một số đoạn đã hình thành các bãi bồi tụ, các cồn cát (đoạn thuộc thị trấn Chợ Vàm và đoạn thuộc xã Phú Lâm, xã Tân Phú huyện Phú Tân). Mặt khác, bờ sông thuộc xã Long Thuận, huyện Hồng Ngự, tỉnh Đồng Tháp lại bị sạt lở nghiêm trọng với các vách sạt lở gần như thẳng đứng. Sạt lở đang uy hiếp tuyến đường liên xã và các hộ dân xây nhà sát bờ sông. Do đó cần có phải pháp hạn chế tại các vị trí sạt lở và đo đạc quan trắc diễn biến tại các vị trí có nguy cơ nhằm có biện pháp khắc phục. Mục tiêu của nghiên cứu này là đánh giá hiện trạng sạt lở và ảnh hưởng của dao động cao độ nước dưới đất đến ổn định bờ sông Cái Vừng, huyện Hồng Ngự, tỉnh Đồng Tháp.

\section{Phương pháp nghiên cứu}

\subsection{Khu vục nghiên cúu}

Sông Cái Vừng là một nhánh của sông Tiền, được phân dòng bởi cù lao Cái Vừng. Điểm bắt đầu của sông Cái Vừng ứng với đầu cù lao Cái Vừng chảy xuôi về hạ lưu đến đuôi cù lao Cái Vừng thì nhập lưu trở lại với sông Tiền. Sông Cái Vừng có hình thái rất khúc khuỷu, tính theo đường sông thì chiều dài của sông Cái Vừng khoảng $21,25 \mathrm{~km}$, còn nếu tính theo đường thẳng chim bay từ điểm đầu sông đến điểm cuối sông chỉ dài khoảng gần $12,78 \mathrm{~km}$. Khu vực nghiên cứu thuộc xã Long Thuận và xã Phú Thuận $\mathrm{A}$, huyện Hồng Ngự, tỉnh Đồng Tháp, cách trung tâm thành phố Hồng Ngự khoảng $7,5 \mathrm{~km}$ và cách thị xã Tân Châu khoảng $8,5 \mathrm{~km}$. Tọa độ 104'57,5" độ Bắc; 105¹7'56,6” độ Đông. Phía đông Bắc giáp xã Long Thuận, huyện Hồng Ngự. Phía đông Nam giáp xã Phú Thuận A, huyện Hồng Ngự. Phía tây Bắc giáp xã Long Hòa, huyện Phú Tân (An Giang), và xã Long Thuận, huyện Hồng Ngự. Phía tây Nam giáp xã Long Hòa, huyện Phú Tân (An Giang) (Hình 1). 


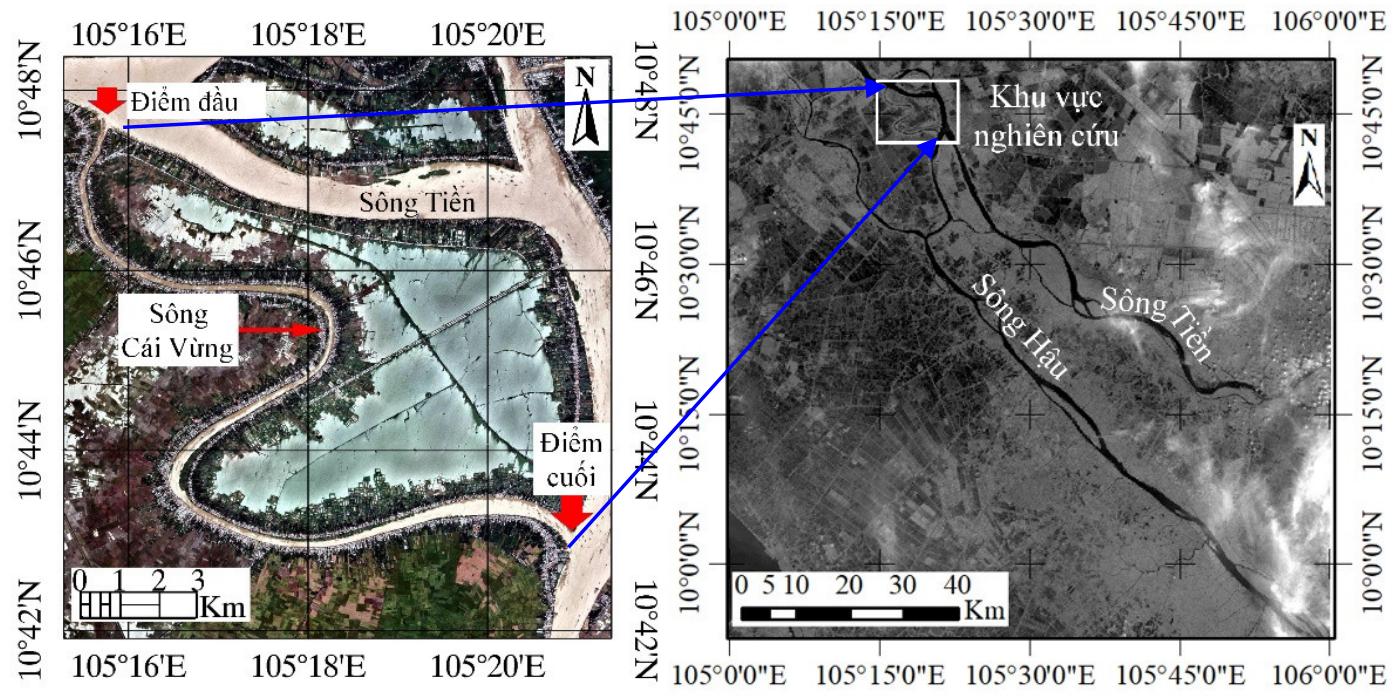

Hình 1. Khu vực nghiên cứu.

\subsection{Thu thập số liệu}

Số liệu được thu thập từ các nguồn như trình bày trong Bảng 1.

Bảng 1. Số liệu và nguồn số liệu.

\begin{tabular}{clcl}
\hline STT & \multicolumn{1}{c}{ Tên số liệu } & Thời gian & \multicolumn{1}{c}{ Nguồn } \\
\hline 1 & Số liệu sạt lở & $2015-2020$ & Chi cục Thủy lợi tỉnh Đồng Tháp \\
2 & Thủy văn (mực nước) & $2000-2020$ & Trạm KTTV tỉnh Đồng Tháp \\
3 & Địa chất & 2020 & Ban QLDACTNN tỉnh Đồng Tháp \\
\hline \multicolumn{2}{l}{ Trạm KTTV tỉnh: Trạm khí tượng thủy văn tỉnh; Ban QLDACTNN tỉnh: Ban Quản lý Dự án Nông nghiệp tỉnh. }
\end{tabular}

\subsection{Khảo sát và đo mặt cắt ngang kết hợp đo vận tốc dòng chảy}

Vận tốc dòng chảy được đo tại nhiều thủy trực trên từng mặt cắt sử dụng thiết bị đo lưu tốc MIDAS-ECM. Thiết bị MIDAS-ECM là thiết bị đo vận tốc tự ghi có thể đo được vận tốc dòng chảy theo hai phương. Trong nghiên cứu này, vận tốc được đo theo phương pháp đo 06 điểm trên thủy trực và vận tốc bình quân thủy trực được tính theo công thức:

$$
\mathrm{v}_{\mathrm{tb}}=\frac{\left.\mathrm{v}_{\mathrm{m}}+2 \mathrm{v}_{0,2}+2 \mathrm{v}_{0,4}+2 \mathrm{v}_{0,6}+2 \mathrm{v}_{0,8}+\mathrm{v}_{\mathrm{d}}\right)}{10}
$$

Trong đó $\mathrm{v}_{\mathrm{m}}$ và $\mathrm{v}_{\mathrm{d}}$ lần lượt là vận tốc dòng chảy tại vị trí mặt nước và gần đáy sông $(\mathrm{m} / \mathrm{s})$; các vận tốc còn lại ứng với các độ sâu $0,2 \mathrm{~h} ; 0,4 \mathrm{~h} ; 0,6 \mathrm{~h}$ và $0,8 \mathrm{~h}$; với h là chiều sâu cột nước tại vị trí đo.

\subsection{Thu mẫu bùn cát đáy sông}

Nhằm xác định cấp phối hạt bùn cát đáy và bờ sông, các mẫu bùn cát được thu thập và lưu trữ trong các hộp nhựa. Các mẫu bùn cát này sau đó được chuyển đến phòng thí nghiệm để xác định cấp phối theo phương pháp rây sàng và lắng đọng. Vị trí lấy mẫu tại các vị trí đoạn sông bị uốn cong và những địa điểm thường xảy ra xói/sạt lở. Trên một mặt cắt sông, các vị trí lấy mẫu bùn cát được xác định như sau: vị trí 01 : cách bờ phải $5 \mathrm{~m}$; vị trí 02 : cách bờ phải $10 \mathrm{~m}$; vị trí 03 : cách bờ trái $10 \mathrm{~m}$; vị trí 04 : cách bờ trái $5 \mathrm{~m}$. Vị trí đo mặt cắt, vận tốc và thu mẫu bùn cát đáy được thể hiện trên Hình 2 . 


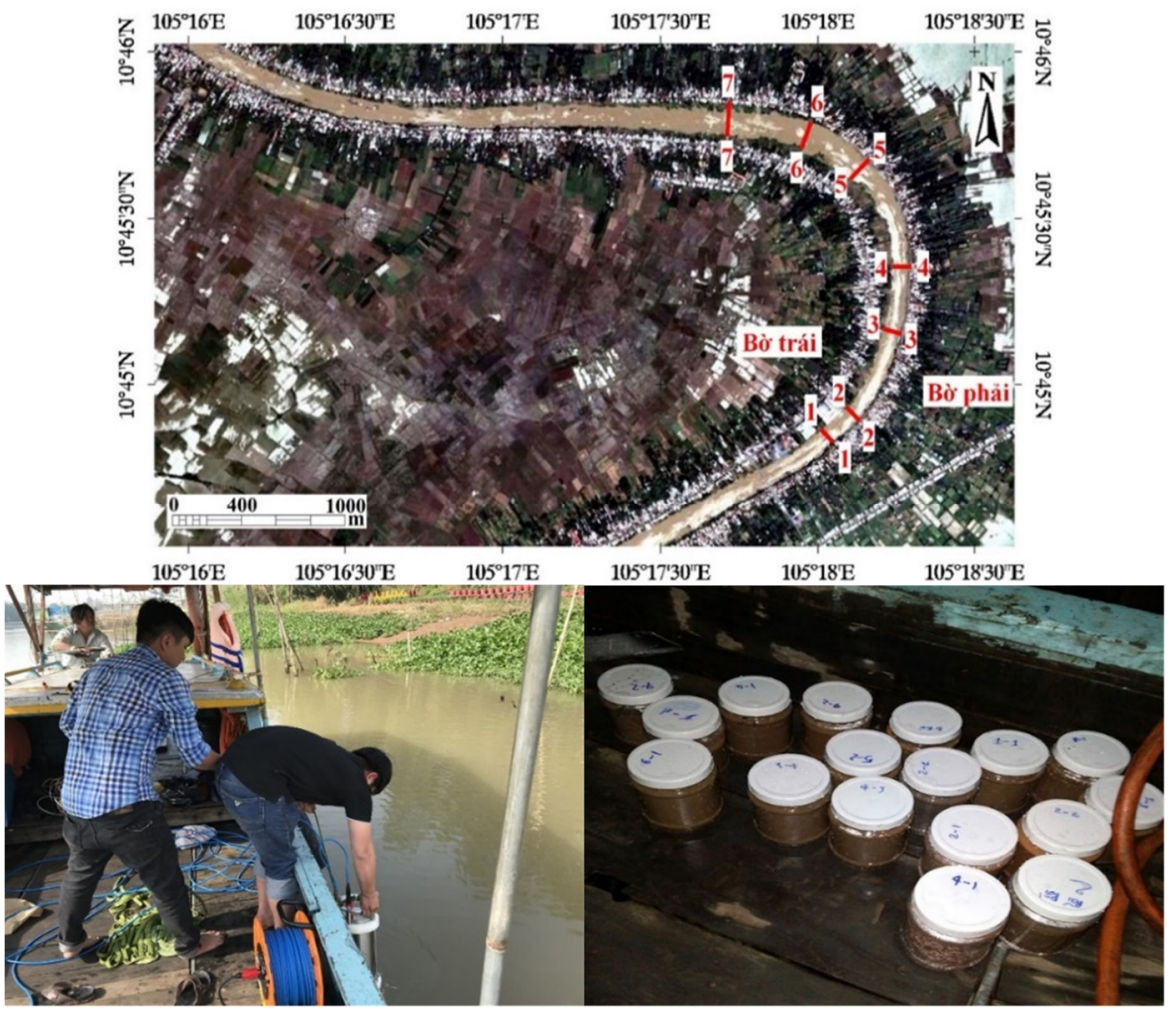

Hình 2. Vị trí đo mặt cắt, vận tốc và thu mẫu bùn cát đáy.

\section{5. Đo dao động mưc nước}

Sơ đồ và vị trí các điểm đo cao độ mực nước dưới đất và nước sông được thể hiện trên Hình 3. Cao độ nước sông và nước dưới đất được quan trắc từ ngày 23/01/2021 đến hết ngày 28/02/2021 theo tần suất 5 lần trong một ngày vào các khung thời gian 7 giờ, 10 giờ, 12 giờ, 15 giờ và 17 giờ. Tương quan giữa cao độ nước dưới đất và nước sông được thiết lập theo phương pháp Pearson [14]: hệ số tương quan đạt giá trị $\mathrm{R}=0,63$ thể hiện mối tương quan mạnh giữa cao độ nước dưới đất và nước sông (Hình 4).

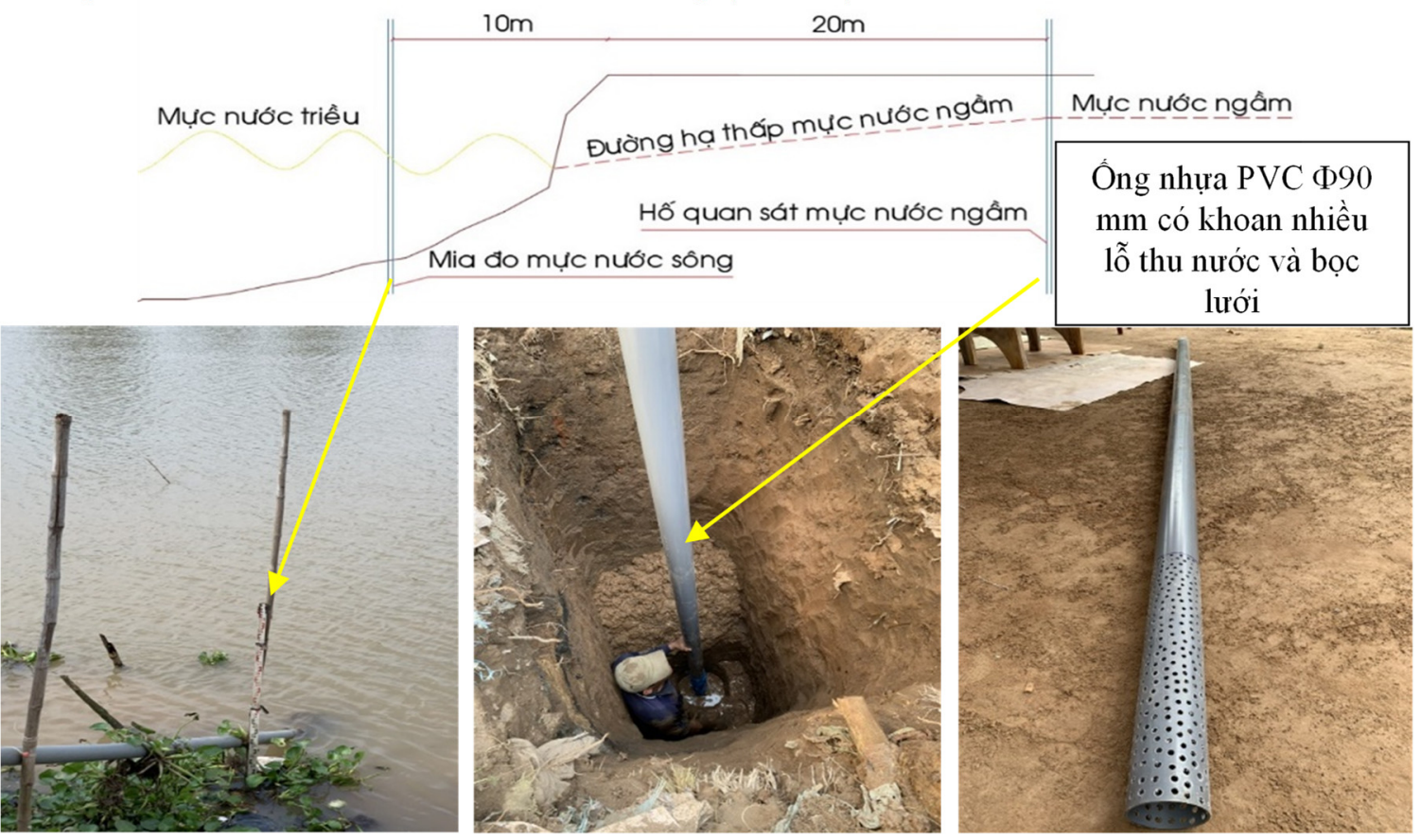

Hình 3. Sơ đồ và vị trí các điểm đo cao độ mực nước dưới đất và nước sông. 


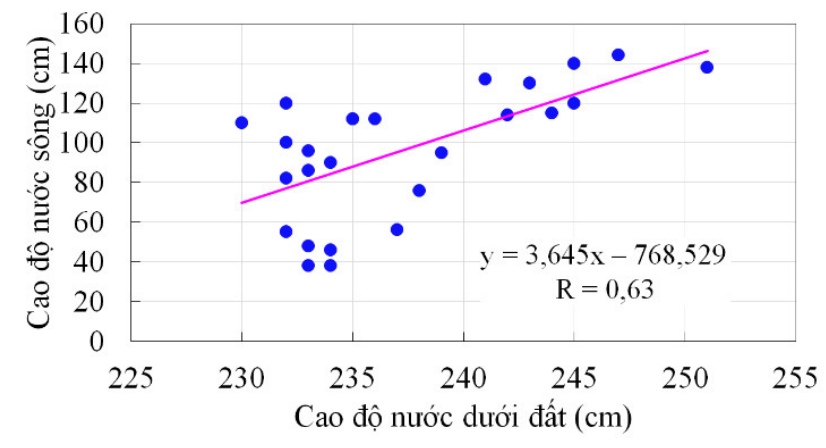

Hình 4. Phương trình quan hệ giữa cao độ nước sông và nước dưới đất.

Sông Cái Vừng nằm trên nhánh của con Sông Tiền cách trạm đo thủy văn Tân Châu chỉ khoảng $20 \mathrm{~km}$. Tương quan mực nước thấp nhất (Hmin) tại trạm Tân Châu với mực nước thấp nhất tại vị trí khảo sát được thiết lập có hệ số tương quan $\mathrm{R}=0,858$ và có phương trình:

$$
y=1,343 x+17,003
$$

Từ phương trình tương quan (Hình 4) và phương trình (2) ta tính toán và được bảng tổng hợp các tần suất mực nước tương quan từ trạm Tân Châu về sông Cái Vừng và từ sông Cái Vừng qua cao độ nước dưới đất (Bảng 2). Từ đó, cao độ nước sông Cái Vừng và nước dưới đất trong điều kiện mực nước thấp nhất $\left(\mathrm{H}_{\min }\right)$ với các tần suất $99 \%, 95 \%$ và $90 \%$ được tính toán.

Bảng 2. Tương quan mực nước.

\begin{tabular}{ccccc}
\hline \multirow{2}{*}{ TT } & \multirow{2}{*}{ Tần suất xuất hiện } & \multicolumn{3}{c}{ Cao độ mục nước (cm) tại: } \\
\cline { 3 - 5 } & & Tân Châu & Cái Vùng & Nước dưới đất \\
\hline 1 & $99 \%$ & $-66,46$ & $-72,25$ & 283,71 \\
2 & $95 \%$ & $-57,98$ & $-60,86$ & 275,74 \\
3 & $90 \%$ & $-53,66$ & $-55,06$ & 271,95 \\
\hline
\end{tabular}

\subsection{Vận tốc không xói cho phép}

Vận tốc không xói cho phép là vận tốc lớn nhất mà dòng chảy đạt tới trị số ấy không gây ra sự xói lở lòng kênh. Vận tốc không xói cho phép phụ thuộc vào tính chất cơ lý của đất nơi tuyến kênh đi qua, lượng ngậm phù sa và tính chất phù sa của dòng chảy trong kênh; lưu lượng của kênh, kích thước mặt cắt ngang của kênh và các yếu tố thuỷ lực của dòng chảy trong kênh. Theo Gônsarôp [15], giá trị của vận tốc khởi động $\mathrm{v}_{\mathrm{k}}$, tức là vận tốc trung bình bé nhất của dòng chảy để hiện tượng bắt đầu tách các hạt đơn độc của đất không dính trên đáy được xảy ra một cách liên tục, được xác định theo công thức (3) và (4):

- Khi tổ hợp của đất là đồng nhất:

$$
\mathrm{v}_{\mathrm{k}}=\lg \frac{8,8 \mathrm{H}}{\mathrm{d}} \sqrt{\frac{2 \mathrm{~g}\left(\gamma_{1}-\gamma_{\mathrm{n}}\right) \mathrm{d}}{1,75 \gamma_{\mathrm{n}}}}
$$

- Khi tổ hợp của đất tại đáy lòng dẫn là không đồng nhất:

$$
\mathrm{v}_{\mathrm{k}}=\frac{2 \mathrm{~g}\left(\gamma_{1}-\gamma_{\mathrm{n}}\right) \mathrm{d}_{\mathrm{tb}}}{1,75 \gamma_{\mathrm{n}}} \lg \frac{8,8 \mathrm{H}}{\mathrm{d}_{5}}
$$

Trong đó $\mathrm{d}$ là đường kính hạt $(\mathrm{mm}) ; \mathrm{d}_{5}$ là đường kính của các hạt lớn nhất chiếm $5 \%$ toàn bộ lượng bùn cát $(\mathrm{mm}) ; \mathrm{d}_{\mathrm{tb}}$ là đường kính trung bình của hỗn hợp bùn cát $(\mathrm{mm}) ; \gamma_{1} ; \gamma_{\mathrm{n}}$ lần lượt là trọng lượng thể tích của bùn cát và nước $\left(\mathrm{kN} / \mathrm{m}^{3}\right)$; và $\mathrm{H}$ là chiều sâu dòng chảy (m).

\subsection{Phân tích ổn định bò̀ sông}


Hệ số ổn định được xác định theo phương pháp Bishop (1955) [16]:

$$
\mathrm{K}_{\mathrm{at}}=\frac{\sum\left[\mathrm{C}_{\mathrm{i}} \times \mathrm{L}_{\mathrm{i}}+\mathrm{W}_{\mathrm{i}} \times \cos \alpha_{\mathrm{i}} \times \operatorname{tg} \varphi_{\mathrm{i}}\right]}{\sum \mathrm{W}_{\mathrm{i}} \times \sin \alpha_{\mathrm{i}}}
$$

Trong đó $C_{i}$ là lực dính của mảnh/thỏi thứ $i$ trong phạm vi chiều dài cung trượt; $L_{i}$ là chiều dài cung trượt thứ $i ; W_{i}$ là trọng lượng mảnh/thỏi thứ $i ; \alpha_{i}$ là góc nghiêng của mảnh/thỏi thứ $i$ so với phương tại tâm trượt; $\varphi_{i}$ là góc nội ma sát của mảnh/thỏi thứ $i$ trong phạm vi chiều dài cung trượt.

Hệ số ồn định cho các trường hợp xem xét (Bảng 2) tại các mặt cắt được tính toán và so sánh với giá trị cho phép [17].

\section{Kết quả và thảo luận}

\subsection{Mặt cắt lòng sông}

Vị trí đo các mặt cắt ngang sông được thể hiện như trên Hình 5 với bờ phải của sông Cái Vừng được quy ước là phía Đồng Tháp và bờ trái là phía An Giang. Từ Hình 5 cho thấy đáy sông bị lệch hẳn về phía bờ phải và có khuynh hướng ngày càng áp sát bờ, đáy sông cách bờ phải khoảng $30 \mathrm{~m}$ và cách bờ trái khoảng $100 \mathrm{~m}$, cao trình đáy sông là $-13,0 \mathrm{~m}$ so với cao trình đỉnh bờ phải là $+5,5 \mathrm{~m}$. Các mặt cắt đều có dấu hiệu sạt lở ăn sâu vào bên trong bờ. Mặt cắt 5-5 nằm giữa đoạn sông cong là mặt cắt nguy hiểm nhất, cao trình đáy sông là $-13,23 \mathrm{~m}$ và cách bờ phải $30 \mathrm{~m}$, sạt lở ăn sâu vào tuyến đường nhựa giao thông liên xã, mái bờ thẳng đứng với hệ số mái $\mathrm{m}<0,5$. Bờ trái của bờ sông tương đối thoải, không bị ảnh hưởng của xói lở và xuất hiện dấu hiệu của các bãi bồi. Như vậy, các mặt cắt khảo sát cho thấy hiện tượng xói lở và bồi tụ điển hình của một đoạn sông cong; trong đó, bờ phải sông Cái Vừng thuộc khu vực khảo sát đang bị xói lở với mái dốc của bờ sông nằm trong khoảng $\mathrm{m}=2 \div 4$, và tại bờ trái, bờ sông có độ dốc tương đối thoải với $\mathrm{m}=6$.
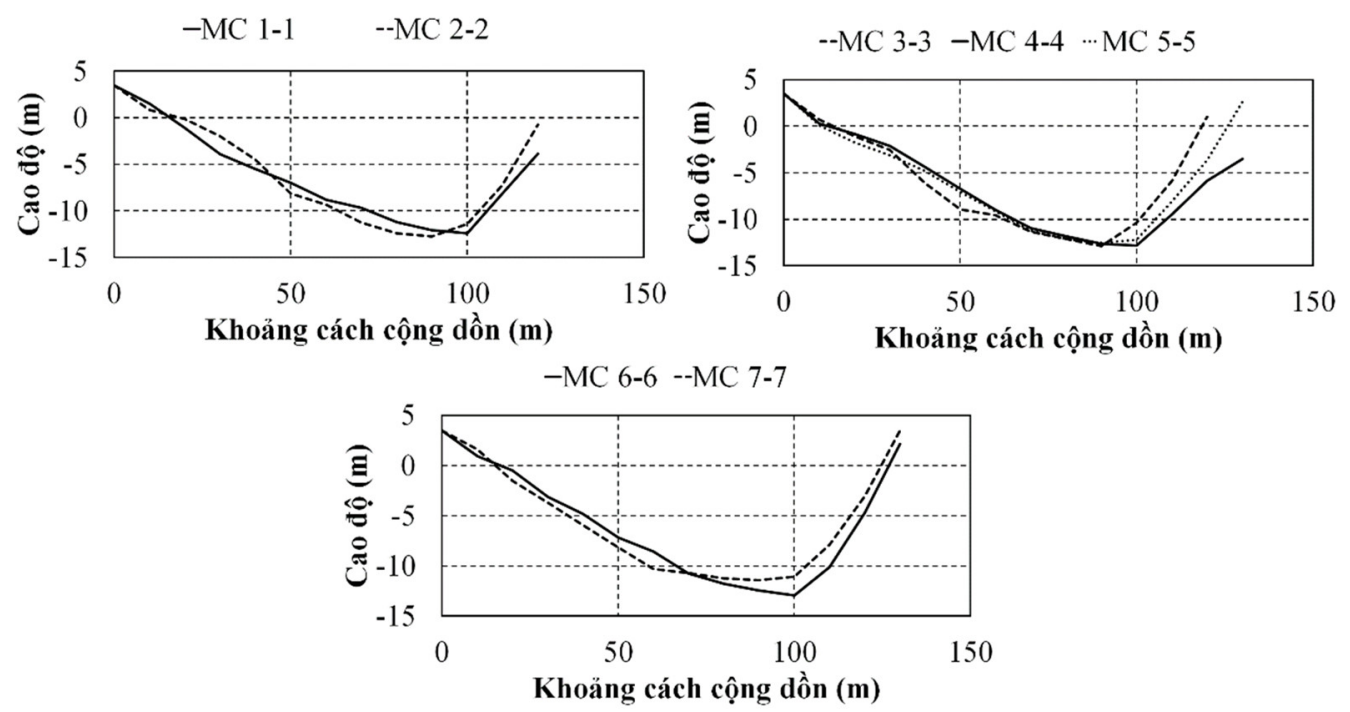

Hình 5. Hình dạng các mặt cắt lòng sông tại khu vực nghiên cứu.

\subsection{Vận tốc dòng chảy}

Từ kết quả đo vận tốc dòng chảy tại khu vực nghiên cứu, sử dụng phương pháp nội suy ta có phân bố vận tốc dòng chảy trên các mặt cắt như trên Hình 6 . Từ Hình 6 ta thấy vận tốc dòng chảy phân bố lệch về phía bờ phải là phía sau của đoạn sông cong. Điều này phù hợp với hình dạng uốn khúc rất lớn của đoạn sông khu vực khảo sát. Tại các đoạn sông cong, vận tốc dòng chảy có hai thành phần là vận tốc dọc bờ và vận tốc ngang bờ. Chính thành phần 
vận tốc ngang bờ là nguyên nhân gây ra xói lở bờ sông. Điều này lý giải cho việc sạt lở nghiêm trọng đang diễn ra tại bờ phải của sông Cái Vừng khu vực khảo sát các mặt cắt.

Tại các mặt cắt $\mathrm{MC}$ 1-1, MC 2-2 và $\mathrm{MC} 3-3$ vận tốc dòng chảy phân bố trong khoảng từ $0,125 \mathrm{~m} / \mathrm{s}$ đến $0,375 \mathrm{~m} / \mathrm{s}$. Tại mặt cắt $\mathrm{MC}$ 4-4 là mặt cắt nằm tại vị trí cong nhất của đoạn sông, vận tốc dòng chảy tăng lên đến $0,625 \mathrm{~m} / \mathrm{s}$. Đến mặt cắt MC 6-6 và $\mathrm{MC} 7-7$, vận tốc dòng chảy lại giảm xuống và phân bố từ $0,125 \mathrm{~m} / \mathrm{s}$ đến $0,375 \mathrm{~m} / \mathrm{s}$.

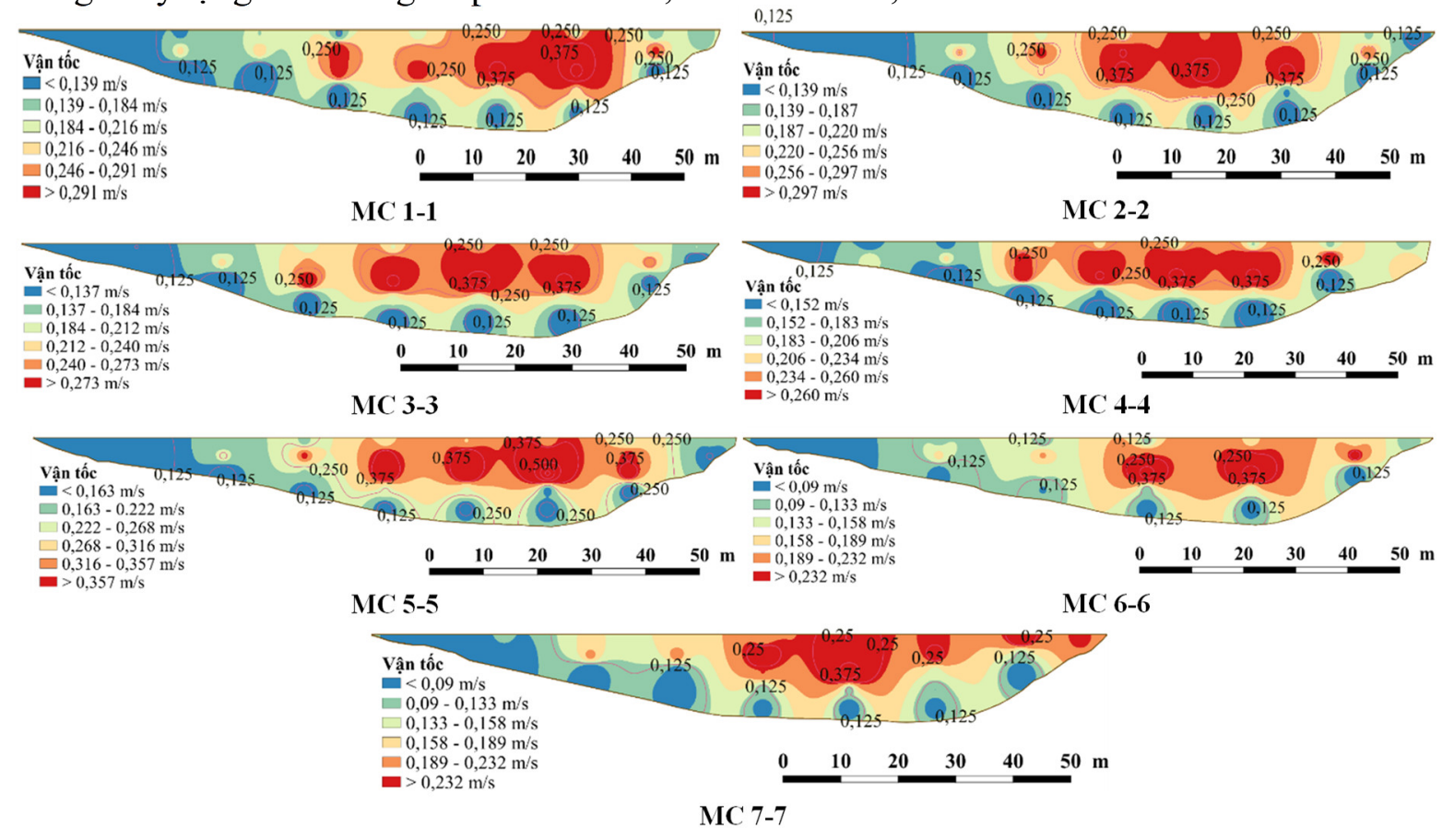

Hình 6. Phân bố vận tốc dòng chảy tại các mặt cắt.

\section{3. Đưòng cong cấp phối bùn cát đáy sông}

Qua khảo sát thực tế, phạm vi sạt lở chỉ nằm trong đoạn sông cong từ $\mathrm{MC} 2-2$ đến $\mathrm{MC}$ 6-6. Vì vậy, thành phần hạt bùn cát tại bờ phải của các mặt cắt từ $M C$ 2-2 đến $\mathrm{MC}$ 6-6 sẽ được sử dụng để phân tích ảnh hưởng của vận tốc dòng chảy đến xói lở bờ sông và được thể hiện trên Hình 7 . Từ Hình 7 ta thấy đường kính hạt trung bình $\left(\mathrm{d}_{50}\right)$ của mẫu bùn cát tại $\mathrm{MC}$ 4-4 có giá trị nhỏ nhất và bằng $0,038 \mathrm{~mm}$, và tại $\mathrm{MC} 2-2$ và $\mathrm{MC} 3-3$ là lớn nhất và bằng 0,06 $\mathrm{mm}$.

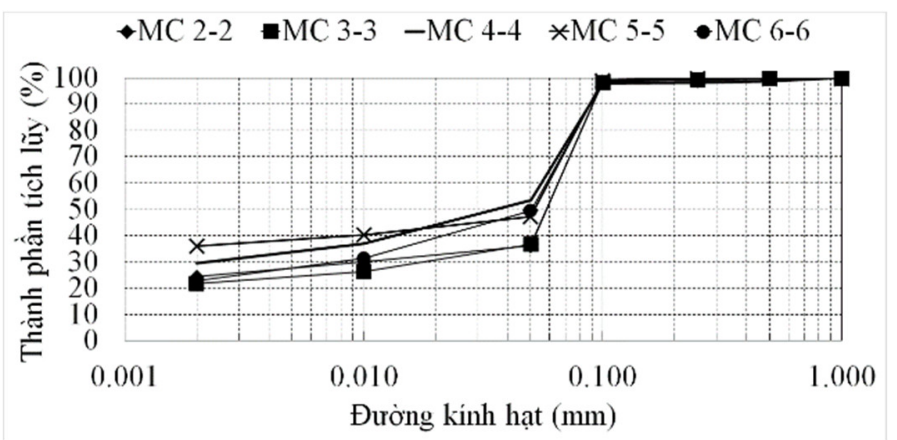

Hình 7. Đường cong cấp phối hạt tại bờ phải MC 2-2 đến MC 6-6.

Theo TCVN 4118:2012 [18], ta có bảng xác định vận tốc không xói ( $\left.\mathrm{V}_{\mathrm{kx}}\right)$ theo kích thước hạt trung bình của bùn cát và chiều sâu cột nước trong sông $(\mathrm{h}>3 \mathrm{~m})$ (Bảng 3$)$. Từ Bảng 3 ta thấy xói lở bờ sông sẽ không xảy ra tại $\mathrm{MC}$ 2-2 và $\mathrm{MC}$ 3-3 vì vận tốc dòng chảy đo được tại các mặt cắt nhỏ hơn so với vận tốc không xói của bùn cát. Tuy nhiên, vận tốc dòng chảy chỉ được khảo sát trong một ngày 21/01/2021 nên cần khảo sát thêm số liệu vận 
tốc vào mùa lũ để có thể đánh giá chính xác ảnh hưởng của vận tốc dòng chảy đến xói lở tại các mặt cắt này. Theo số liệu thực đo ngày $21 / 01 / 2021$, xói lở do dòng chảy chỉ xảy ra trong phạm vi từ $\mathrm{MC}$ 4-4 đến $\mathrm{MC}$ 6-6. Điều này phù hợp với kết quả khảo sát thực tế ngày 21/01/2021 là đoạn sông cong từ MC 4-4 đến MC 6-6, xói lở đang xảy ra rất nghiêm trọng và hiện đang triển khai xây dựng các kè bảo vệ bờ tại khu vực này (Hình 8 ).

Bảng 3. Giá trị d50, $\mathrm{V}_{\mathrm{kx}}$ và $\mathrm{V}$ tại các vị trí dọc bờ phải sông Cái Vừng.

\begin{tabular}{cccc}
\hline Mặt cắt (bò̀ phải) & $\mathbf{d}_{\mathbf{5 0}}(\mathbf{m m})$ & $\mathbf{V}_{\mathbf{k x}}(\mathbf{m} / \mathbf{s})$ & $\mathbf{V}(\mathbf{m} / \mathbf{s})$ \\
\hline $2-2$ & 0,060 & $0,26 \div 0,40$ & $0,125 \div 0,375$ \\
$3-3$ & 0,060 & $0,26 \div 0,40$ & $0,125 \div 0,375$ \\
$4-4$ & 0,038 & $0,19 \div 0,26$ & $0,375 \div 0,625$ \\
$5-5$ & 0,054 & $0,19 \div 0,26$ & $0,125 \div 0,375$ \\
$6-6$ & 0,053 & $0,19 \div 0,26$ & $0,125 \div 0,375$ \\
\hline
\end{tabular}

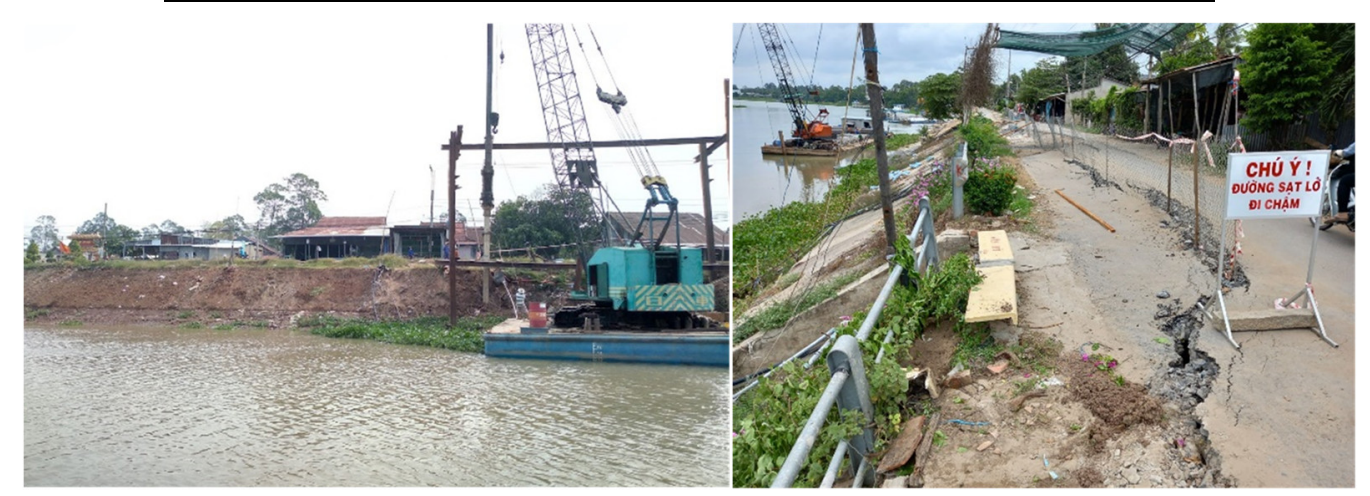

Hình 8. Xói lở bờ sông tại khu vực khảo sát.

\subsection{Phân tích ổn định bò̀ sông}

Hệ số ổn định được xác định theo công thức (5) và kết quả được thể hiện trên Hình 9. Từ Hình 9 ta thấy hệ số ổn định trong cả ba trường hợp tính toán cho các mặt cắt đều không đảm bảo an toàn khi $\mathrm{K}_{\mathrm{at}}$ luôn nhỏ hơn 1,2 [13]. Như vậy, chênh lệch cao độ nước sông và nước dưới đất là một trong những nguyên nhân gây ra sạt lở bờ sông Cái Vừng.

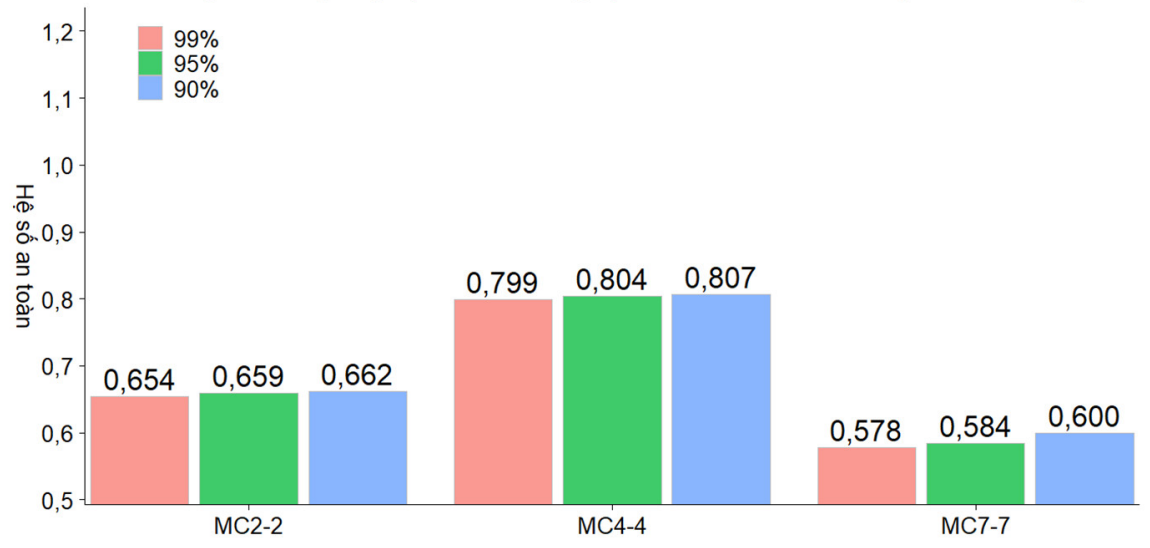

Hình 9. Hệ số ổn định các trường hợp tính toán.

\section{Kết luận}

- Đoạn sông thuộc khu vực nghiên cứu có hình thái của một đoạn sông cong. Kết quả khảo sát vận tốc dòng chảy cũng cho thấy vận tốc dòng chảy tại bờ phải của đoạn sông trong khu vực khảo sát có giá trị lớn hơn $(0,375 \mathrm{~m} / \mathrm{s})$ so với vận tốc dòng chảy bên bờ trái $(0,125$ $\mathrm{m} / \mathrm{s})$. 
- Dựa vào kích thước cỡ hạt trung bình $\left(\mathrm{d}_{50}=0,038 \div 0,060 \mathrm{~mm}\right)$ của bùn cát đáy sông và chiều sâu cột nước trong sông Cái Vừng $(\mathrm{h}>3 \mathrm{~m})$, vận tốc khởi động của bùn cát đáy sông trong khoảng $0,19 \mathrm{~m} / \mathrm{s} \div 0,40 \mathrm{~m} / \mathrm{s}$.

- Tại thời điểm khảo cho thấy vận tốc dòng chảy chỉ đủ lớn để gây ra xói lở tại vị trí đoạn sông cong nhất từ MC 4-4 đến MC 6-6. Tuy nhiên, đây chỉ là kết quả đo trong một thời đoạn ngắn vào ngày $21 / 01 / 2021$ nên cần có thêm các kết quả khảo sát dòng chảy vào mùa lũ để đánh giá đầy đủ hơn về khả năng gây xói bờ sông do dòng chảy.

- Kết quả tính toán cho thấy hệ số an toàn trong các trường hợp đều nhỏ hơn hệ số an toàn cho phép.

Đóng góp của tác giả: Xây dựng ý tưởng nghiên cứu: L.H.B., L.V.T., T.V.T.; Lựa chọn phương pháp nghiên cứu: L.H.B., L.V.T., T.V.T.; Xử lý số liệu: L.H.B., D.V.D., L.H.T.; Phân tích mẫu: T.V.T., L.V.T., L.H.T.; Lấy mẫu: L.H.B., D.V.D., T.V.T.; Viết bản thảo bài báo: L.H.B., H.V.T.M, D.V.D., T.V.T.; Chỉnh sửa bài báo: H.V.T.M., L.V.T., T.V.T., D.V.D.

Lời cam đoan: Tập thể tác giả cam đoan bài báo này là công trình nghiên cứu của tập thể tác giả, chưa được công bố ở đâu, không được sao chép từ những nghiên cứu trước đây; không có sự tranh chấp lợi ích trong nhóm tác giả.

\section{Tài liệu tham khảo}

1. Anthony, E.J.; Brunier, G.; Besset, M.; Goichot, M.; Dussouillez, P.; Lap, N.V. Linking rapid erosion of the Mekong River delta to human activities. Sci. Rep. 2015, 5(1), 1-12.

2. Minh, H.V.T.; Kurasaki, M.; Ty, T.V.; Tran, D.Q.; Le, K.N.; Avtar, R.; Rahman, M.M.; Osaki, M. Effects of Multi-Dike Protection Systems on Surface Water Quality in the Vietnamese Mekong Delta. Water 2019, 11, 1010.

3. Thu, V.C.; Sơn, N.T.; Tuấn, N.C.; Ninh, L.V.; Việt, C.T.; Tuấn, L.A. Nghiên cứu khả năng áp dụng công thức kinh nghiệm để tính toán mức độ xói lở bờ sông ở Đồng bằng sông Cửu Long - Thí điểm tại đoạn xói lở bờ sông Hậu ở Long Xuyên, tỉnh An Giang. Tạp chi Khí twợng Thủy văn 2021, 728, 31-39.

4. Hùng, L.M. Nghiên cứu dự báo xói lở, bồi lắng lòng dẫn và đề xuất các biện pháp phòng chống cho hệ thống sông Đồng bằng sông Cửu Long. Báo cáo tổng hợp đề tài KC08-15/01-05, 2004.

5. Nga, T.N.Q.; Thuận, L.T.; Hoài, H.C.; Bảy, N.T. Nghiên cứu ứng dụng mô hình toán và công thức kinh nghiệm đánh giá sự phát triển của hố xói sâu hạ lưu sông Hậu và sông Vàm Nao. Tạp chí Khí tượng Thủy văn 2020, 5, 1-10.

6. Hùng, L.M.; Hoằng, T.B.; Khang, N.D.; Anh, T.T. Kết quả ứng dụng mô hình SWAT trong tính toán xói lở bề mặt lưu vực hạ lưu sông Mekong. Tạp chí Khoa họ và Công nghẹ Thủy lợi 2012, 12, 25-32.

7. Hùng, L.M.; Ngọc, Đ.T.B. Công thức kinh nghiệm tính tốc độ xói lở bờ đoạn sông Tiền khu vực Thường Phước, tỉnh Đồng Tháp. Tạp chí Nông nghiẹp và Phát triển nông thôn 2004, 6, 787-796.

8. Hải, H.Q.; Trinh, V.T.M. Tương quan xói lở - Bồi tụ một số khu vực lòng sông Tiền, sông Hậu. Tạp chí các khoa học về Trái đất 2011, 33(1), 37-44.

9. Hoàng, T.P.; Hùng, P.T. Mối quan hệ giữa khai thác cát với biến động bờ sông Tiền tại tỉnh Đồng Tháp. J. Sci. 2016, 12(4), 92-103.

10. Lộc, N.Đ.; Linh, L.T.C.; Minh, H.V.T.; Luận, T.C.; Tho, N.V.; Hưng, V.V.; Tỷ, T.V. Xác định nguyên nhân sạt lở bờ sông theo phương pháp khảo sát thực địa: nghiên cứu tại sông Cái Sắn, thành phố Cần Thơ. Tạp chí Xây dựng 2020, 7, 146-151.

11. Hoành, T.P. Đánh giá thực trạng và nguyên nhân xói lở bờ sông Tiền đoạn chảy qua tỉnh Đồng Tháp. Khoa học Tụ nhiên \& Công nghệ 2015, 20, 61-67. 
12. Hùng, L.M.; Sản, Đ.C.; Chương, L.T.; Long, N.T.; Hoàng, T.B.; Tường, T.N.; Nguyên, L.Đ.; Việt, P.B.; Khiết, Đ.V. Báo cáo tổng kết dự án NCKH cấp Nhà nước: Nghiên cứu dự báo phòng chống xói lở bờ sông Cửu Long, Viện Khoa học Thủy lợi Miền Nam, TP. Hồ Chí Minh, 2001, tr. 338.

13. Điển, N.V.; Nhàn N.T. Báo cáo kết quả khảo sát địa hình: Đo đạc, giám sát đánh giá ổn định bờ sông Tiền và thiết lập hành lang sạt lở tại khu vực đông dân cư và cơ sở hạ tầng trên địa bàn tỉnh Đồng Tháp, 2019, 1-70.

14. Schober, P.; Boer, C.; Schwarte, L.A. Correlation Coefficients: Appropriate Use and Interpretation. Anesth. Analg. 2018, 126(5), 1763-1768.

15. Kixelep, P.G.; Altsul, A.D.; Danhitsenko, N.V.; Kaxpaxon, A.A.; Griptsenko, G.I.; Paskop, N.N.; Xlixki, X.M. Sổ tay tính toán thủy lực, NXB Xây dựng, 2008, 719.

16. Bishop, A.W. The use of the slip circle in the stability analysis of slopes. Géotechnique 1955, 5(1), 7-17.

17. Bộ Nông nghiệp và Phát triển nông thôn. QCVN 04-05:2012/BNNPTNT Quy chuẩn kỹ thuật quốc gia - Công trình thủy lợi - Các quy định chủ yếu về thiết kế, 2012.

18. Bộ Khoa học và Công nghệ. TCVN 4118 : 2012 Công trình thủy lợi - Hệ thống tưới tiêu - Yêu cầu thiết kế, 2012.

\title{
Research on the impacts of geological, hydrological factors on the stability of riverbanks of Cai Vung river in Hong Ngu district, Dong Thap province
}

\author{
Le Hai Bang ${ }^{1}$, Lam Van Thinh ${ }^{2}$, Le Hai Tri ${ }^{3}$, Dinh Van Duy ${ }^{3}$, Tran Van Ty ${ }^{3^{*}}$, Huynh \\ Vuong Thu Minh ${ }^{2}$ \\ ${ }^{1}$ Department of Agriculture and Rural Development, Dong Thap province; \\ lehaibangcctl@gmail.com \\ ${ }^{2}$ College of Environment and Natural Resources, Can Tho University; \\ lvthinh@ctu.edu.vn; hvtminh@ctu.edu.vn \\ ${ }^{3}$ College of Technology, Can Tho University; tvty@ctu.edu.vn; dvduy@ctu.edu.vn; \\ lehaitri@gmail.com
}

\begin{abstract}
The objective of this study is to assess the current state of riverbank erosion and the impact of groundwater level fluctuation on the stability of Cai Vung riverbank, Hong Ngu district, Dong Thap province. Topographic, geological, and hydrological data were collected and measured to analyze, establish the correlation between groundwater level and river water level; then analyze the cause of riverbank erosion according to stability coefficient. The results show that the prominent causes are the flow, soft soil along with the groundwater level fluctuation. The flow velocity has an eccentric flow distribution, creating maximum velocity near riverbanks which is larger than the allowed non-erosion velocity corresponding to the riverbed grain-size according to the Vietnam standard (TCVN: 41182012). The soft soil layer is within the tidal fluctuation together with the eccentric flow making voids and deepening, causing instability of the riverbank. The coefficient of stability in all cases is less than the allowable value. The results are based on measurement data for a short period of time, it is not possible to fully assess the causes that may affect riverbank erosion. Therefore, it is necessary to monitor continuously or with different seasons to have a more accurate assessment of factors causing the erosion.
\end{abstract}

Keywords: Soft soil; Stability coefficient; Groundwater level fluctuation; Cai Vung river; Flow velocity. 